University of Nebraska - Lincoln

DigitalCommons@University of Nebraska - Lincoln

Faculty Publications, Department of Child, Youth, and Family Studies

Child, Youth, and Family Studies, Department of

2013

\title{
The Mathematical Development in Number and Operation of Struggling First Graders
}

\author{
John Lannin \\ University of Missouri-Columbia, lanninj@missouri.edu \\ Delinda van Garderen \\ University of Missouri-Columbia, vangarderend@missouri.edu \\ Matthew J. Switzer \\ Texas Christian University, j.switzer@tcu.edu \\ Kelley E. Buchheister \\ University of Nebraska - Lincoln, kbuchheister2@unl.edu \\ Tiffany Hill \\ University of Missouri-Columbia, thill7@emporia.edu
}

See next page for additional authors

Follow this and additional works at: https://digitalcommons.unl.edu/famconfacpub

Part of the Disability and Equity in Education Commons, Early Childhood Education Commons, Elementary Education Commons, Science and Mathematics Education Commons, and the Special Education and Teaching Commons

Lannin, John; van Garderen, Delinda; Switzer, Matthew J.; Buchheister, Kelley E.; Hill, Tiffany; and Jackson, Christa, "The Mathematical Development in Number and Operation of Struggling First Graders" (2013). Faculty Publications, Department of Child, Youth, and Family Studies. 317.

https://digitalcommons.unl.edu/famconfacpub/317

This Article is brought to you for free and open access by the Child, Youth, and Family Studies, Department of at DigitalCommons@University of Nebraska - Lincoln. It has been accepted for inclusion in Faculty Publications, Department of Child, Youth, and Family Studies by an authorized administrator of DigitalCommons@University of Nebraska - Lincoln. 


\section{Authors}

John Lannin, Delinda van Garderen, Matthew J. Switzer, Kelley E. Buchheister, Tiffany Hill, and Christa Jackson 
Investigations in Mathematics LeARning

(C) The Research Council on Mathematics Learning

Winter Edition 2013, Volume 6, Number 2

\title{
The MATHEMATICAL \\ DEVELOPMENT IN NUMBER AND OPERATION OF STRUGgLING FIRST GRADERS
}

\author{
John Lannin \\ University of Missouri \\ lanninj@missouri.edu \\ Delinda van Garderen \\ University of Missouri \\ J. Matthew Switzer \\ Texas Christian University \\ Kelley Buchheister \\ University of South Carolina \\ Tiffany Hill \\ University of Missouri \\ Christa Jackson \\ University of Kentucky
}

\section{Introduction and Background of Study}

Number and operations serve as the "cornerstone" of the K-12 mathematics curriculum in many countries. Solving problems in the mathematical domains of algebra, geometry, measurement, and statistics is often closely connected to student knowledge of number and operation (Griffin, 2005). Although considerable knowledge exists regarding the development of number and operation for typically developing children (e.g., Carpenter \& Moser, 1984; Clements, 2007; Fosnot \& Dolk, 2001), less is known about the development of children who struggle in mathematics. Moreover, children enter school with considerable differences in their understandings of number and operation (Klibanoff, Levine, Huttnelocher, Vasilyeva, \& Hedges, 2006). 
While most children, through exposure to various informal and formal tasks, develop a deeper understanding of number and operation, this development is delayed for some children. These children do not achieve levels of proficiency required for higher mathematics (Ginsburg, Inoue, \& Seo, 1999; Griffin, 2007; Jordan, Kaplan, Olah, \& Locuniak, 2006; Jordan, Kaplan, Locuniak, \& Ramineni, 2007). The poor performance of struggling mathematical learners is even more troubling as the consequences of failure in mathematics are serious and far-reaching, even into adulthood (Dougherty, 2003; Woodward \& Montague, 2002). Researchers have found that poor mathematical skills may be a greater handicap than poor literacy skills in the workplace (Butterworth, 2005). Therefore, it is critical that difficulties in mathematics are addressed before they become "chronic, pervasive, severe, and difficult to remediate" (Fuchs, 2005, p. 351).

Over the past decade in particular, researchers have examined the impact of instruction in early number and operations with children in the early grades (ages 5-8) struggling with (e.g., Fuchs, Fuchs, Hamlet, Powell, Capizzei, \& Sethalar, 2006; Funkhouser, 1995; Griffin, 2004; Klein \& Starkey, 2004; Tournaki, 2003; Van Luit \& Scopmann, 2000; Wright, Stewart, Stafford, \& Cain, 1998). Although such studies demonstrated increased performance for children who were struggling or had a learning disability, not all children made adequate progress (e.g., caught up with their peers).

In some studies, concerns regarding student retention of learned concepts, and success generalizing and transferring mathematical ideas to other mathematical situations or domains were noted. Yet, it is unclear why these mixed results occurred. However, one possible explanation may be that the interventions did not involve further consideration of the differences in learning trajectories for struggling learners and, as a result, lack specificity needed to best help children. As Van Luit and Schopmann (2000) noted,

children with special education needs constitute a heterogeneous group. The characteristics, abilities, and deficits of the children vary considerably. As a consequence, children with similar starting competencies may nevertheless differentially benefit from instruction. That is, children with different patterns of cognitive functioning may have different instruction needs

(p. 35). Therefore, they strongly recommended that, "future research should be directed at the role of individual differences in the development of early numeracy and the characteristics of children's learning responsible for these differences" (p. 35).

\section{Summary of the Literature and Related Research}

Detailed learning progressions currently exist regarding typical development in various constructs that contribute to early number and operation 
(e.g., Clements \& Sarama, 2009; Sarama \& Clements, 2009). Accounts, for example, of how children construct knowledge of quantity (e.g., Starkey, 1992), number and counting (e.g., Fuson, 1988; Gelman \& Gallistel, 1978; Ginsburg, Klein, \& Starkey, 1998; Griffin \& Case, 1997), and arithmetic (e.g., Carpenter \& Moser, 1984; Geary, 1994) exist and general patterns of typical development have been established.

Although not as studied as typical development, research focused on children with 'atypical' development, primarily those with a mathematics disability, and their development in number and operation also exists. Researchers have examined the development of children having mathematics learning disabilities (MLD) related to number and operations, specifically in the areas of counting and arithmetic (cf., Geary \& Hoard, 2005) and number sense with an emphasis in magnitude and number quantity (e.g., Butterworth, 1999; Geary, Hoard, Byrd-Craven, Nugent, \& Numtee, 2007; Landerl, Bevan, \& Butterworth, 2004).

From the research, several general patterns of poorer performance in number and operations have been identified. Children with a MLD apply most counting constructs (e.g., 1-1 correspondence, cardinality), but tend to perform poorly in comparison with their typically developing peers on tasks related to order-irrelevance (i.e., items within a given set can be tagged in any sequence) or adjacency (i.e., the erroneous belief that items must be counted consecutively and from one contiguous item to the next) (Geary \& Hoard, 2005). In addition, children with a MLD, unlike their typically developing peers, rely on developmentally immature strategies (e.g., finger counting), count rather than subitise, have difficulty comparing procedures (e.g., counting both addends starting from one rather than counting on from the larger addend), and have difficulty retrieving basic facts from long-term memory and are often slower to do so (Butterworth, 1999; Geary, 2004; Geary \& Hoard, 2005, Geary, Hoard, Nugent, \& Byrd-Craven, 2008; Koontz \& Berch, 1996; Landerl, Bevan, \& Butterworth, 2004; Ostad, 1999).

Differing perspectives as to the causes of these difficulties exist across the extant literature. For example, Geary and colleagues (e.g., Geary, 2004; Geary \& Hoard, 2005) propose that the primary cause of a MLD are deficits with underlying cognitive processes that support conceptual and procedural competencies for solving mathematics problems. Geary attributes children's difficulties to a central executive deficit with working memory. Thus, children have difficulty forming associations to transfer information into longterm memory and representing information in working memory, resulting in a 'cognitive overload' when completing a task. In contrast to Geary's work, Butterworth and colleagues (e.g., Butterworth, 2005; Landerl, Bevan \& Butterworth, 2004) propose that a MLD results from an internal dysfunction of basic numerical cognition that fails to develop normally, resulting in difficulty understanding number concepts (e.g., magnitude, counting 
difficulties, number reading, number comparison) and in learning numerical information. Furthermore, the difficulties these children experience in number have an impact on their ability to learn other mathematical concepts right from the start (Landrl, Fussenegger, Moll, \& Willburger, 2009).

Despite the different perspectives on the causes of a MLD, these and other studies highlight that children with MLD experience various difficulties in mathematics. These studies suggest that not all children have the same difficulties or follow the same developmental trajectory. For example, Geary (2004) identified three subtypes or 'trajectories' of difficulty. They include: (a) a procedural subtype characterized by use of developmentally immature procedures to perform computations, frequent errors in execution of procedures, poor understanding of the concepts underlying procedural use, and difficulty sequencing multiple steps in complex procedures; (b) a semantic memory subtype characterized by difficulties retrieving mathematics facts for simple arithmetic problems, and, for facts retrieved, there is a high error rate the majority of these errors being associates of numbers in the problems (e.g., retrieving 4 for $2+3=$ ?); and (c) a visuospatial subtype characterized by difficulty spatially representing numeral and other forms of mathematical information and relationships as well as frequent misinterpretation or misunderstanding of spatially represented information. According to Geary, the first subtype appears to represent a developmental delay that, for the most part, improves over the course of the elementary schools year. The second subtype, however, represents a developmental difference that does not change substantially across age or grade. In essence, this is considered a permanent cognitive disability and these student's continue to perform substantially lower than their peers without a MLD. We note several concerns with these suggestions.

First, more research is needed to further validate and refind the trajectories of learning (Geary \& Hoard, 2005). In addition, this work needs to extend beyond arithmetic, where the majority of Geary's work is situated. Second, of the current research available focused on number, it is primarily limited to certain early number constructs (e.g., magnitude) and not others (e.g., place value). More importantly, while a persistence of the condition has been acknowledged (e.g., Butterworth, 1999; Ostad, 1999), no studies have characterized the long-term development of a MLD from this theoretical perspective. As a result, the impact of this deficit over time and across other mathematical domains and why some children continue to struggle while others quickly "catch up" in mathematics is unclear (Geary, 1990, 1993, 2004).

In summary, further research is needed into the development of individual children and their instructional needs. Without a deeper understanding of specific skills and concepts that typify struggling learners, instructional interventions that are inappropriate to meet each child's needs (Gersten \& 
Chard, 1999) will continue to promoted and used. As a result, children who struggle in mathematics will continue to lag behind their peers, leading to little progress towards a deeper level of mathematical understanding. In this study, we identify: (a) specific difficulties that exist among children identified as struggling in mathematics for number, and (b) the extent to which these difficulties persisted or diminished following a targeted intervention.

\section{Theoretical Considerations}

To guide our work related to the development of early number knowledge with children struggling in mathematics, we drew on the extant literature (National Research Council, 2001) related to early numeracy, specifically three of the five strands of mathematical proficiency: procedural fluency (i.e., skill in carrying out procedures flexibly, accurately, efficiently, and appropriately), conceptual knowledge (i.e., comprehension of mathematical concepts, operations, and relations) and strategic competence (i.e., ability to formulate, represent, and solve mathematical problems). Though these strands are often portrayed as separate aspects of knowledge, we view these as three intertwined aspects of early number knowledge. We recognize that children typically draw on various strands when approaching a task. Thus, we considered these three strands as critical for better understanding a child's strengths and difficulties with early number: (a) procedural knowledge of counting procedures, (b) conceptual knowledge of number, and (c) strategic competence for representing mathematical situations.

A child's understanding of early number is complex and multidimensional. Numerous core mathematical constructs have been identified in the research literature in mathematics education, special education, and psychology related to early number (e.g., Baroody, 1992; Clements, 2007; Cordes \& Gelman, 2005; Fosnot \& Dolk, 2001; Piaget \& Szeminska, 1952). These constructs include: (a) one-to-one correspondence, (b) cardinality, (c) knowledge of the number system (e.g., identifying the number before or after a particular number, skip counting by $2 \mathrm{~s}, 5 \mathrm{~s}$, and $10 \mathrm{~s}$ ), (d) order irrelevance (i.e., recognizing that you may start counting with any object), (e) conservation of quantity, (f) hierarchical inclusion (i.e., smaller numbers are embedded within larger numbers) and (g) unitizing (i.e., viewing a group of ten as ten objects and one group of ten simultaneously correspondence).

Early number constructs and strands are intertwined, and children often draw on aspects of procedural fluency and conceptual knowledge as they perform tasks related to any one construct. For example, as a child counts objects she must recognize that the idea of touching one object and saying one count (i.e, one-to-one correspondence) is essential for proper counting. In addition, the child must apply a procedure to assure that each object is 
counted once and only once.

Strategic competence is closely linked to the process of representing problem situations. Often representing involves the use and creation of models that serve as an intermediary between the problem and the solution method. A representation can be organized and manipulated in ways that can simply the problem structure and facilitate problem solving. Many seemingly different problem situations can be represented in similar ways (e.g., with fingers or objects) that allow for the abstraction of a particular problem solving strategy, recognizing that a strategy can be applied across problems with particular structure.

\section{Method and Data Sources}

In this study we drew on the findings of a larger study that utilized a teaching experiment approach designed to examine the mathematical development of struggling first graders (ages 6-7 years). This study was conducted in two public elementary schools in a midwestern city in the United States. School A was a Title I school with $80 \%$ of children receiving free or reduced lunch. School B had 34\% of children receiving free or reduced lunch. Teachers identified sixteen first grade children who were struggling in mathematics. These children were racially diverse ( 8 African American, 4 Caucasian, 2 multi-race, and 2 Asian children) and included 9 males and 7 females. The results of 16 children are discussed in this paper.

As background for the teaching experiment, we provide the following information about the instructional sessions (Steffe \& Thompson, 2000). During the teaching experiment we focused on student development of number knowledge (e.g., magnitude, order irrelevance). The teaching experiment included 36 teaching episodes designed to explore and extend the child's mathematical knowledge. During each teaching episode, written notes of each child's reasoning were recorded. This information was used in preparing instruction for the subsequent episodes. Instruction was provided for children in pairs, two times per week (40-50 minutes per session), for approximately 18 weeks. The activities provided during the intervention incorporated various representational forms (e.g., concrete, pictorial, numeric symbols). Figure 1 is an example task designed to help children connect the numeric symbols to a concrete model as they compare two quantities. In addition, the intervention included explicit instruction, emphasizing strategies for solving problems (e.g., how to track what is being counted, steps promoting metacognitive/self-regulation actions for solving a problem) and opportunity for practice and review (Kroesbergen \& Van Luit, 2003; Swanson, 1999; Montague \& van Garderen, 2008). 


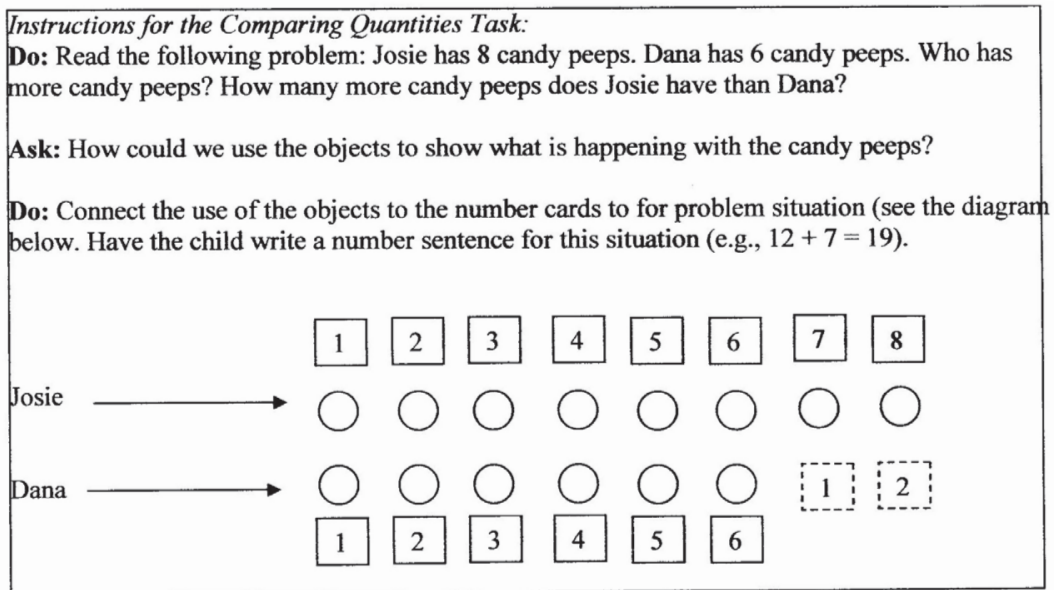

Figure 1.

Comparing Quantities Task.

In this manuscript, we focus on the pre- and post-assessment findings for the children who participated in this study. In the following paragraphs we characterise the children we studied, elaborating on the measure used to assess student understanding about number and operations, and describe our data analysis techniques. To assess student understanding about number and operations, a researcher-designed instrument, the Early Number Battery (ENB), was used. The ENB included 43 tasks targeting one or more mathematical constructs (e.g., one-to-one correspondence, knowledge of the counting sequence, magnitude, conservation of quantity), drawing from various resources, including Fosnot and Dolk (2001), Sarama and Clements (2009). Figure provides examples of various tasks in the ENB.

The pre-tests were carried out during the Fall (September) and the posttests during Spring (April). The children were individually interviewed using task-based interviewing process (Goldin, 1997) that allowed for followup questions to clarify the strategies and thinking of the child. Children were allowed to respond orally, draw diagrams, or used manipulatives during portions of the interview.

All student responses were noted in field notes and analyzed following the interview. Using a data reduction approach (Miles \& Huberman, 1994), we analyzed individual data for each child from the ENB on three levels. For each child, we created summaries of their pre-, and post-ENB performance for each construct, describing children' procedural, conceptual, and strategic competence related to each construct on the ENB. (See the Appendix for the descriptors of the procedural and conceptual knowledge for various constructs.) Second, the children's strategies were categorized as high, low, or mixed based on their overall performance related to procedural 


\begin{tabular}{|c|c|}
\hline Construct & Sample Assessment Task \\
\hline Magnitude & $\begin{array}{l}\text { Place in front of the child the number " } 41 \text { " card and the number } \\
\text { "14" card. } \\
\text { Ask: "Which is less, } 41 \text { or } 14 \text { ?" } \\
\text { Ask: "How do you know (child's response) is less?" } \\
\text { Place in front of the child the number " } 41 \text { " card and the number } \\
\text { "14" card. } \\
\text { Ask: "Which is smailer?" } \\
\text { Ask: "How do you know (child's response) is smaller?" }\end{array}$ \\
\hline Number Recognition & $\begin{array}{l}\text { Say: "I am going to show you a number then I want you to read } \\
\text { the number." } \\
\text { Show number cards one at a time: } 3,7,12,18,21,29,43,64,81 \text {, } \\
145 \text {, and } 316 \text {. }\end{array}$ \\
\hline Conservation of Quantity & $\begin{array}{l}\text { Part } A . \\
\text { Lay out } 15 \text { blocks in a pile. (If child cannot count beyond 10, use } \\
10 \text { blocks.) } \\
\text { Say: "Count these blocks." After the child has counted the blocks: } \\
\text { Arrange the blocks in a long line. } \\
\text { Ask: "How many blocks are there now?" (Record response.) } \\
\text { Part B. } \\
\text { Make a group of the } 15 \text { blocks. } \\
\text { Ask: "How many blocks are there now?" (Record response.) }\end{array}$ \\
\hline Hierarchical Inclusion & $\begin{array}{l}\text { Put out } 5 \text { counters under your hand. Place one counter on the table } \\
\text { uncovered. } \\
\text { Say: "I have } 5 \text { counters under my hand. There is one other } \\
\text { counter." Keep counters covered and: } \\
\text { Ask: "How many counters are there all together?" (Record } \\
\text { response.) } \\
\text { Ask: "How did you know how many counters were under my } \\
\text { hand?" (Record response.) }\end{array}$ \\
\hline
\end{tabular}

Figure 2.

Simple tasks from the ENB.

knowledge, conceptual knowledge, and strategic competence. These categories were coded independently by two of the authors. Any discrepancies in coding were discussed and resolved. The children were then organized into groups based on the similarity of performance on the pre-assessment (e.g., high procedural knowledge, low conceptual knowledge, low strategic competence). Last, we analyzed each child's post-ENB performance in order to characterise the changes in knowledge that occurred for each child.

\section{Results}

In the following sections, we identify student difficulties that emerged through our analysis. All children demonstrated difficulty with more than 
one of the targeted constructs in the study. However, no child demonstrated difficulty with the constructs related to one-to-one correspondence (i.e., recognizing that for each item touched, one count should be uttered) and cardinality (i.e., identifying the last count as the number of objects). We identified four primary groups: (a) Group 1 children with strong conceptual knowledge and strong procedural fluency, but poor strategic competence ( 3 children), (b) Group 2 children with strong procedural fluency and poor conceptual knowledge and strategic competence (2 children), (c) Group 3 children with poor conceptual knowledge, procedural fluency, and strategic competence ( 7 children), and (d) Group 4 children with mixed conceptual knowledge and procedural fluency, and poor strategic competence (4 children). (See Tables 1, 2, and 3 for a summary of pre- and post assessment performance for each group.) Below we characterise the specific difficulties on the preassessment for each group and describe the extent to which these specific difficulties persisted or diminished during first grade.

\section{Group 1: Strong Conceptual Knowledge and Procedural Fluency, but} Poor Strategic Competence

\section{Pre-assessment performance for Group 1.}

Procedural fluency. The children in this group were categorized as strong procedurally because they demonstrated relatively strong knowledge of the counting sequence, properly tracked counted objects, and skip counted by twos and tens. These children, despite their strong knowledge of comparing quantities, did not use a reliable procedure for comparing more than two numerals.

The three children in this group correctly counted to 30 and most counted beyond 30. Additionally, they provided the correct number word for the "number before" or the "number after" number words through 100. Also, each child properly tracked objects while counting for various arrangements (e.g., creating "counted" and "uncounted" piles). These children skip counted by twos to 10 and tens to 90 , but were unsuccessful counting by fives.

When asked to sequence six numerals from smallest to largest, these children compared numerals in pairs, demonstrating a lack of knowledge of a valid procedure for comparing multiple quantities. For example, when asked to compare $18,1,12$, and 4 , they ordered the group $1,18,4,12$, comparing the 18 and 1 , then 12 and 4 without considering how each pair related to other pairs.

Conceptual knowledge. Children in this group demonstrated relatively strong conceptual knowledge, correctly applying one-to-one correspondence (i.e., touching each object and starting a count for all objects counted), order irrelevance (i.e., recognizing that after counting 15 objects that if the 
Table 1.

Procedural Fluency of the Four Groups of Struggling Children on the Pre and Post Assessments.

\begin{tabular}{|c|c|c|c|c|c|c|}
\hline & \multirow{2}{*}{ 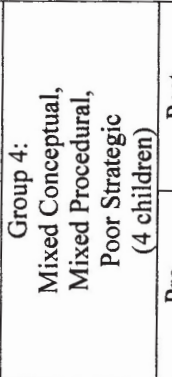 } & 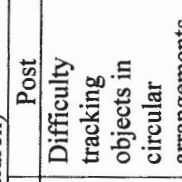 & 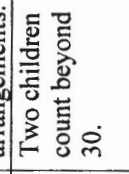 & 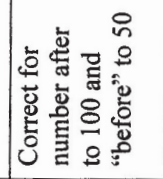 & 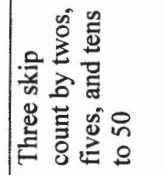 & 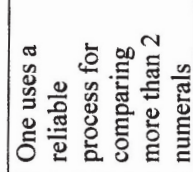 \\
\hline & & 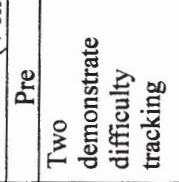 & 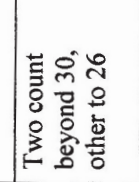 & 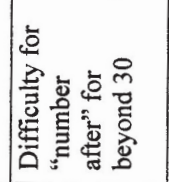 & 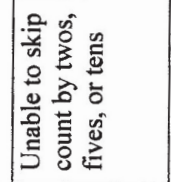 & 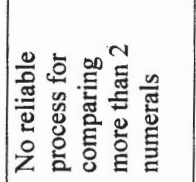 \\
\hline & \multirow{4}{*}{ 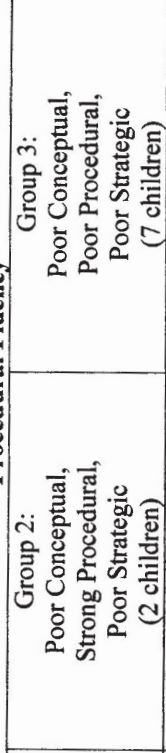 } & 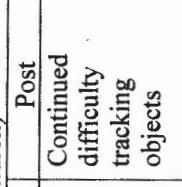 & 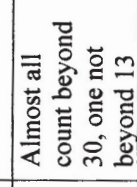 & 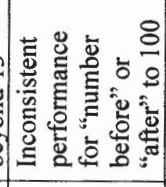 & 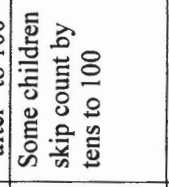 & 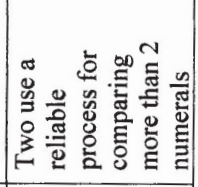 \\
\hline & & 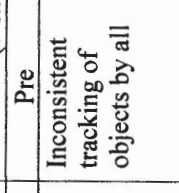 & 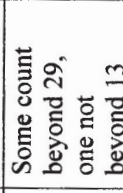 & 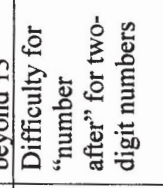 & 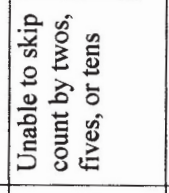 & 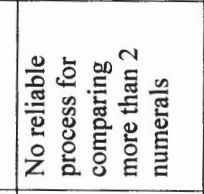 \\
\hline & & 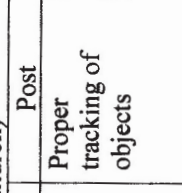 & 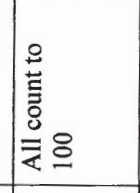 & 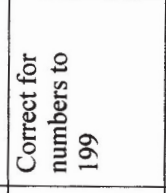 & 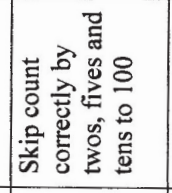 & 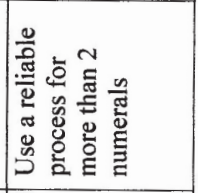 \\
\hline & & 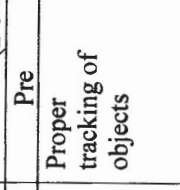 & 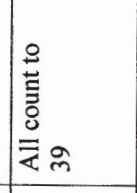 & 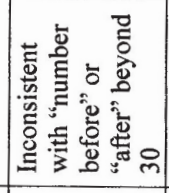 & 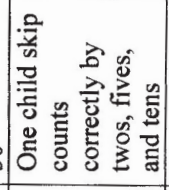 & 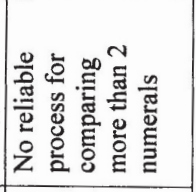 \\
\hline \multirow{3}{*}{\multicolumn{2}{|c|}{ 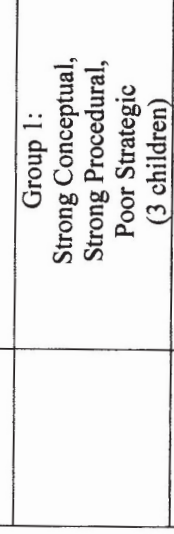 }} & 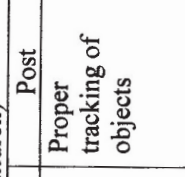 & 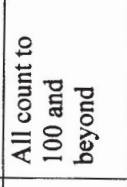 & 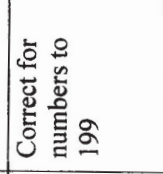 & 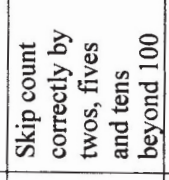 & 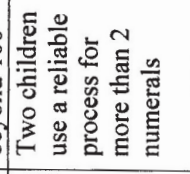 \\
\hline & & 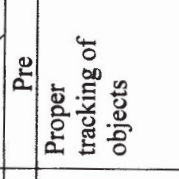 & 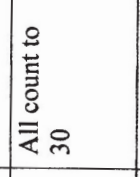 & 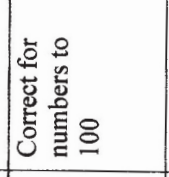 & 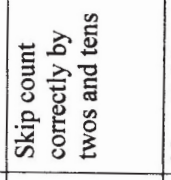 & 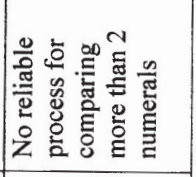 \\
\hline & & 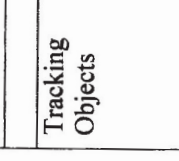 & 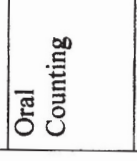 & 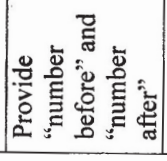 & 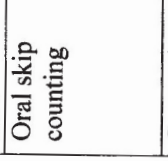 & 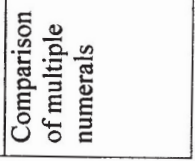 \\
\hline
\end{tabular}


Table 2.

Conceptual Knowledge of the Four Groups of Struggling Children on the Pre and Post Assessments.

\begin{tabular}{|c|c|c|c|c|c|c|c|c|c|}
\hline & 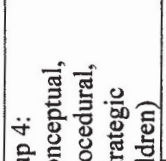 & 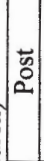 & 춘 & 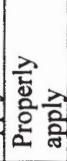 & 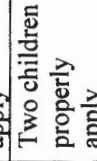 & 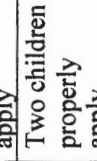 & 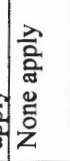 & 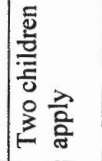 & 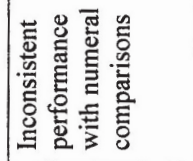 \\
\hline & 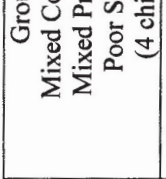 & 2 & $\begin{array}{l}\frac{2}{2} \\
\frac{2}{2} \\
\frac{2}{2} \\
\frac{2}{2} \\
0 \\
0 \\
0\end{array}$ & 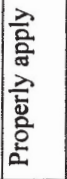 & 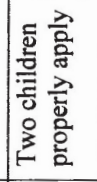 & 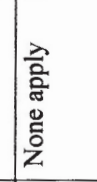 & $\begin{array}{l}\frac{2}{2} \\
\text { 몀 } \\
0 \\
0 \\
z \\
z\end{array}$ & $\begin{array}{l}\frac{2}{2} \\
\frac{2}{0} \\
\frac{1}{0} \\
0 \\
0 \\
z\end{array}$ & 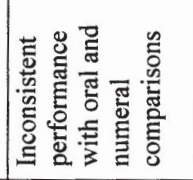 \\
\hline & 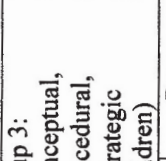 & (1) & 롱 & 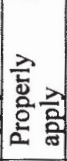 & 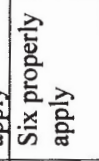 & 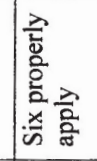 & 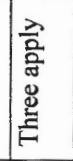 & 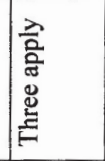 & 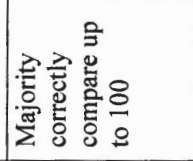 \\
\hline 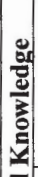 & $\left|\begin{array}{cccc}0 & 0 & 0 & 0 \\
0 & 0 & 2 & 0 \\
5 & 5 & 0 & 0 \\
0 & 0 & 0 & 0 \\
0 & 0\end{array}\right|$ & 2 & 홓 & 종 & $\begin{array}{l}\frac{2}{2} \\
\frac{a}{a} \\
0 \\
0 \\
0 \\
2 \\
2\end{array}$ & $\begin{array}{l}\frac{1}{2} \\
\frac{1}{0} \\
0 \\
0 \\
0 \\
z\end{array}$ & $\mid \begin{array}{l}\frac{2}{2} \\
\frac{a}{a} \\
\frac{\pi}{2} \\
0 \\
z \\
z\end{array}$ & $\begin{array}{l}\frac{2}{2} \\
\frac{0}{2} \\
\frac{1}{1} \\
0 \\
0 \\
0 \\
z\end{array}$ & 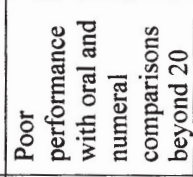 \\
\hline$=$ & 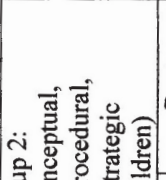 & $\mid$ & 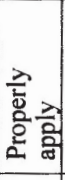 & 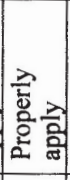 & 紊 & 窎 & $\begin{array}{l}\frac{2}{2} \\
\frac{2}{2} \\
0 \\
0 \\
0 \\
0 \\
z\end{array}$ & 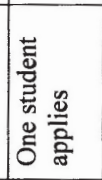 & 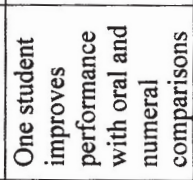 \\
\hline & 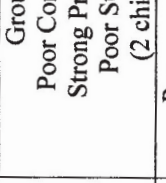 & 2. & $\begin{array}{l}\text { 궁 } \\
\frac{1}{0} \\
\frac{1}{2} \\
\frac{2}{2} \\
\frac{0}{0} \\
0\end{array}$ & 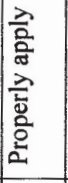 & 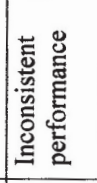 & 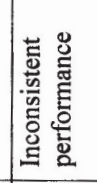 & $\begin{array}{l}\frac{\pi}{2} \\
\text { 高 } \\
0 \\
0 \\
z \\
z\end{array}$ & 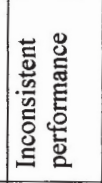 & 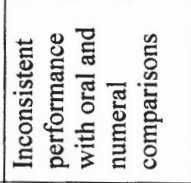 \\
\hline & 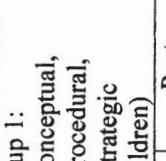 & 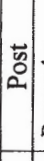 & 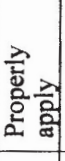 & 줄 & $\begin{array}{l}\frac{\lambda}{5} \\
\frac{2}{0} \\
0 \\
0\end{array}$ & 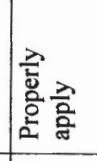 & 춯 & 을흘 흘 & 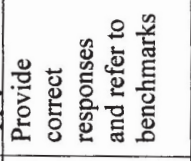 \\
\hline & 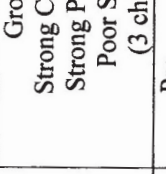 & 2. & 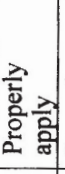 & 홍 & 㐘 & 룰 & 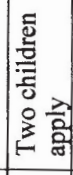 & 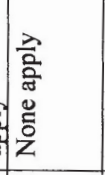 & 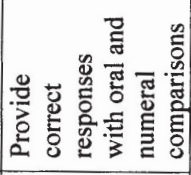 \\
\hline & & & 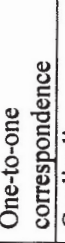 & 槖 & 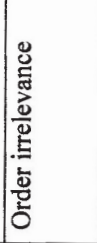 & 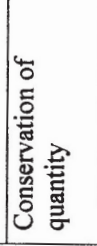 & : & 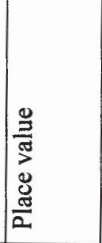 & 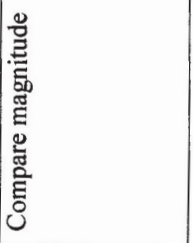 \\
\hline
\end{tabular}


Table 3.

Strategic Competence of the Four Groups of Struggling Children on the Pre and Post Assessments.

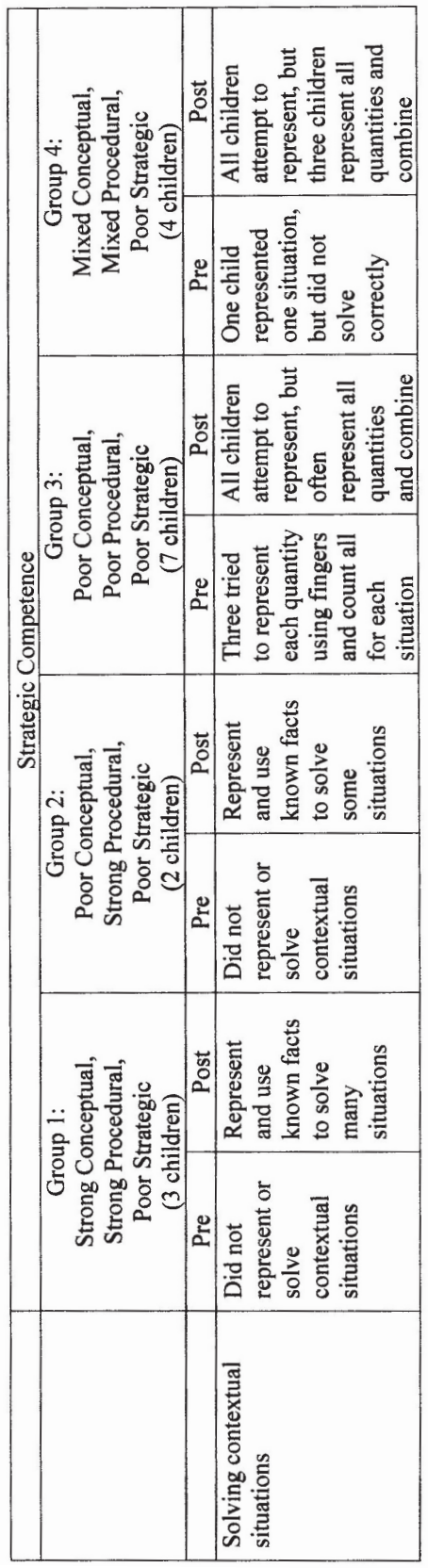

counted in a different order the result would still be 15 objects), cardinality (i.e., that the last count represented the total number of objects), and conservation of quantity (i.e., recognizing that rearranging objects did not change the number of object). Two children unitised (e.g., viewed objects as 2 groups of 10 and 20 objects simultaneously) but had a little understanding of place value when given numerals. For example, two of 3 children recognized that, when 30 objects were placed into six groups of five, that there were six groups of five objects, and 30 objects total. For place value, after counting 23 objects, the children were asked to indicate what the " 2 " means in the numeral "23"; all children pointed to two objects. They correctly compared numerals, but had difficulty explaining why one number was greater then another. For example, one child stated, "14 is smaller because the 41 is far away from the 14."

Strategic competence. All children in this group demonstrated low performance with regard to strategic competence. When provided various contextual word problems, no child successfully represented or solved any situation provided. For example, when asked to determine the number of balloons altogether given 6 red and 6 green balloons, one child created two piles of 6 objects, but stated there were 6 balloons altogether.

Post-assessment performance for Group 1.

Procedural fluency. All children in this group continued to correctly count objects and extended the counting sequence into the hundreds. In addition, 
these children applied skip-counting strategies when counting objects. For example, when counting a group of 12 objects one child began counting by ones until he reached six, then correctly counted the remainder of objects by twos (stating "8, 10, 12"). These children extended their knowledge of the number sequence, correctly providing the "number before" or the "number after" given number words through 199. In addition, these children correctly counted by twos, fives, and tens beyond 100 .

In contrast to the pre-assessment performance where no children in this group applied a correct procedure for ordering more than two numerals, one child had difficulty applying a procedure to compare quantities and continued to compare quantities in pairs. The other two children ordered the entire set correctly by starting with the smallest numeral and determining the next largest numeral in the set.

Conceptual knowledge. Children in this group continued to correctly apply one-to-one correspondence, order irrelevance, and conservation of quantity. In addition, all children recognized that a group of objects could be represented in more than one way, identifying that six groups of five objects consisted of six groups and 30 objects.

Two of 3 children demonstrated a deeper understanding of place value. After counting 23 objects these children recognized that the "2" in 23 represented twenty objects and that the " 3 " mean three objects. When comparing quantities, these children successfully compared quantities into the hundreds. Their justifications involved references to decades and centuries as benchmarks. For example, when comparing 356 and 712 one child responded that 712 , "is smaller than 1000, but bigger than 700 ".

Strategic competence. In the post-assessment all children improved their performance related to representing and solving contextual problems. When asked to determine the number of balloons altogether when given 6 red and 6 green balloons, these children either represented this situation with objects or drew on known facts (e.g., 6 and 6 is 12). They had difficulty with the situation that required them to find the total number of candies given 3 bags of candies with 10 in each bag and 4 extra candies. However, they correctly represented missing addend tasks (e.g., given 7 items, how many more to make 10) and solved comparison situations (e.g., given 14 candies and another person has 8 candies, how many more candies do you have? by drawing diagrams.

\section{Group 2: Strong Procedural Fluency but Poor Conceptual Knowledge} and Strategic Competence

Pre-assessment performance for Group 2.

Procedural fluency. The two children in this group demonstrated relatively strong procedural fluency. They properly tracked objects when counting and counted to 39 using the correct number words. In addition, they 
correctly identified the "number after" for numbers less than 30 , although they did not consistently identify the "number before" in the same range. One child correctly skip counted by twos (to 20), fives (to 100) and tens (to 100). However the other child was unable to skip by twos, fives, or tens. In addition, though these children correctly compared two numerals, they did not use a reliable procedure for comparing more than two numerals.

Conceptual knowledge. Both children demonstrated poor conceptual understanding of the constructs assessed. They recognized and applied one-toone correspondence and cardinality. However, they did not realize that the number of objects in a group stayed the same regardless of the order in which objects were counted. The children in this group needed to recount objects when they were rearranged in different configurations, demonstrating poor understanding of conservation of quantity. When asked to determine the number of groups and the number of objects when given six groups of five objects, they focused on the number of groups and did not identify the total number of objects. In addition, their understanding of place value was limited, pointing to two objects when asked what the "2" in 23 represented.

On oral magnitude tasks, both children demonstrated some magnitude knowledge, but were unable to consistently apply or express why a number was greater than or less than another. For example, when asked which number, 16 or 25 , was greater, one student indicated 16 was greater "because 16 is the most of 25." One child correctly identified the greater or lesser numeral for single-digit numbers, but demonstrated difficulty comparing larger numerals. For example, she stated that "53" and "35" were the same because "they have threes and fives." At times, she identified the larger value based on the placement of the digits. For example, when asked to identify the greater numeral between 16 and 25, she correctly identified 25 because the card was "to the right" of 16 . In contrast, the other child correctly identified the greater or lesser numeral for various two-digit numbers. However, her explanations for all 2 and 3-digit numerals consistently involved superficial understanding of magnitude, comparing the left most digit. For example, when asked why 615 was greater than 235, her response was "because 6 is bigger than 2" without referencing the value of the digit.

Strategic competence. When presented with contextualized problems, they were unable to solve problems correctly and failed to represent situations with diagrams or objects.

Post-assessment performance of Group 2.

Procedural fluency. Although these children demonstrated a relatively strong procedural knowledge on the pre-assessment, they progressed by the end of first grade. They continued to properly track objects when counting. They counted correctly through the counting sequence to 100, developed more sophisticated ways of counting (e.g., counting objects by groups of three or two), and correctly identified the "number before" or the "number 
after" for two and three-digit number words up to 199. They correctly skip counted by twos, fives, and tens to 100 . In addition, both children used a reliable process for comparing more than two numerals, starting with the least numeral and determining the next greater numeral.

Conceptual knowledge. On the post-assessment both children made progress towards developing a deeper conceptual understanding of the constructs examined. As stated previously, they correctly applied one-toone correspondence and cardinality. Now, however, when confronted with tasks involving order irrelevance, both children recognized that the order of counting objects did not change the result. Furthermore, they correctly applied conservation of quantity.

The children made gains in unitising as both children identified the quantity in each group and utilized skip counting tens to determine the total. But, when asked to determine the number of groups and the number of objects when given six groups of five objects, they continued to focus on the number of groups and did not identify the total number of objects. Their performance was inconsistent for place value and magnitude items. For place value, one child demonstrated progress when asked to show what the "2" represented in the number 23 with objects, noting, "that makes twenty" and counted out twenty objects. The other child did not demonstrate such understanding.

Strategic competence. Both children demonstrated positive shifts in representing various contextualized word problems. For example, one child solve the task with 6 red and 6 green balloons by writing and equation " $6+6$ $=12$ " and on another task she counted on as noted in her explanation, "three because I counted on $8,9,10$." The other child used objects to represent the problem situations, but exhibited difficulty relating his representation to the situation. For example, to determine the total number of gummy bears that Andrew was given by his sister when he had seven to begin with and finished with 10, the child created a group of 7 objects and another of 10 objects and incorrectly combined the quantities in an attempt to solve the problem.

Group 3: Poor Procedural Knowledge, Conceptual Knowledge, and Strategic Competence

Pre-assessment performance for Group 3

Procedural fluency. Overall, the children in this group demonstrated relatively little procedural knowledge for the constructs examined. While all children demonstrated one-to-one correspondence, the majority ( 5 of 7 ) demonstrated difficulty in keeping track of the items counted. They tended to rearrange objects in unsystematic ways or tried to count objects without moving them into "counted" and "uncounted" groups. In addition, these children demonstrated a range of performance in reciting the counting se- 
quence. For example, some counted beyond 29, but did not skip correctly by twos, fives, or tens. Three children were unsuccessful counting beyond 29 (one child was inconsistent counting beyond 13) or skip counting. When asked the "number after" a particular number word, only one child responded correctly for number words less than 25 , the majority ( 6 of 7) correctly identified the "number after" for single-digit number words. For the "number before," 6 of 7 responded incorrectly, often stating the "number after" (e.g., for the number before 3 they stated 4).When asked to order more than 620 numerals, they were unsure how to compare multiple numerals, tending to simply rearrange the numerals with no apparent process.

Conceptual knowledge. These seven children performed poorly for most constructs. They recognized that they needed to count one object and say one count (one-to-one correspondence) and that the last count represented the total number of objects (cardinality). However, none responded correctly to order irrelevance tasks. When objects were rearranged, no child demonstrated evidence of conservation of quantity, as they started they were unsure whether the total number of objects remained the same. In addition, no child demonstrated an understanding the meaning of the " 2 " in 23 as 20 (place value). For unitising, the majority (6 of 7) of children did not correctly identify the number of groups and the total number of objects. For magnitude, no child consistently identified the greater or lesser of two numbers words or numerals beyond 20 .

Strategic competence. No child correctly solved any of the contextualized word problems presented. Of the 7 children, three attempted to solve these situations by counting on their fingers by representing each quantity in the situation and counting all, but had difficulty dealing with situations where the total was greater than 10 .

Post-assessment performance for Group 3.

Procedural fluency. In contrast to the pre-assessment, all children properly tracked objects. In addition, nearly all children (6 of 7) recited the counting sequence to 30 . While the children demonstrated evidence of a wide range of performance skip counting by twos, fives, and tens, nearly half ( 3 of 7) showed some proficiency, and the majority counted by 10 s to 100. For the tasks involving determining the "number after" a particular number word, all children correctly stated the correct response for number words to 30 with three children correctly for number words to 100 . For the "number before" tasks all children demonstrated some improvement, however, they performance was inconsistent. For example, one child provided the correct number word for numbers to 30 but was unable to do so for larger number words (e.g., for 100, able to state 99). Two children consistently identified the "number before" for number words to 100 . The majority (5 of 7 ) of children demonstrated difficulty keeping track of counted objects. These children continued to have difficulty comparing more than two numerals, 
though two children used the procedure of determining the last numeral, then choosing the next greater numeral.

Conceptual knowledge. As with the pre-assessment, all children properly applied one-to-one correspondence and cardinality. In addition, six children correctly applied order irrelevance by stating that the number of objects in a counted pile remained the same whether the order of counting objects changed or not. Likewise, 6 of 7 children stated that the number of objects remained the same when objects were rearranged, demonstrating an understanding of conservation of quantity. For unitising, nearly half of the children ( 3 of 7 ) stated that the number of groups or the number of objects was the same as the total number of objects. Three of 7 children stated that the 2 in 23 meant 20, demonstrating an understanding of place value for ones and tens.

For magnitude, the majority of children (4 of 7) identified both the greater and least of two number words. Likewise, the majority (4 of 7) of children identified the greater or least of two numerals. These children provided an explanation that supported their answer (e.g., "because [712] is about to one thousand"). The children who had some difficulty with those tasks (greater or least) often responded correctly for one- or two-digit numbers. Further, they typically did not provide proper justifications for their responses (e.g., "It's [58] huge" and "I don't know").

Strategic competence. All children demonstrated some level of strategic competence by answering at least one question (out of 5 situations) correctly. Two children answered two tasks correctly and one child responded correctly for three tasks. While not all representations were properly modeled, 6 of 7 children utilized some representational form (e.g., tally marks, diagram, fingers, equation, objects) to represent and solve these problems. They demonstrated marked improvement from the pre-assessment where few children attempted to represent any contextual problem. One child was particularly strong with representing situations. When asked to determine the total number of M\&Ms ( 3 bags of 10 plus 4 more), this child drew 3 boxes with $10 \mathrm{M} \& \mathrm{Ms}$ in each and then drew four circles to represent the additional M\&Ms.

Group 4: Mixed Conceptual Knowledge and Procedural Fluency, and Poor Strategic Competence

Pre-assessment performance of Group 4.

Procedural fluency. Two children in this group recited the counting sequence beyond thirty when counting objects, but these two children had difficulty "keeping track" when counting objects. The other two children in this group did not correctly orally count through counting sequence beyond 26. In addition, 3 of 4 children properly identified the "number after" various number words under 30 . The other child identified the "number after" 
number words to 10 . No child in this group skip-counted by twos, fives, or tens. In addition, these children demonstrated difficulty comparing more than two numerals, choosing numerals in an unorganized manner.

Conceptual knowledge. The children in this group properly applied oneto-one correspondence and cardinality. One child in this group identified the greater when given two number words. However, the other two children performed inconsistently and did not explain how they determined whether values were greater. In addition, no child compared numerals consistently, appearing to select the greater numeral based on the largest digit in a numeral. Two of 4 children noted that, when counting objects, that starting with a different object as the first count would not change the total quantity. However, when asked about the impact on the quantity when rearranged, all children were unsure whether the quantity was conserved. When objects were placed into six groups of five, no Group 4 child distinguished between the number of groups and the number of objects in a group. In addition, none of the children demonstrated place value understanding regarding the meaning of the "2" digit in the number 23.

Strategic competence. No child in Group 4 solved the contextualized word problems that were provided. One child correctly represented a problem situation that included finding the total number of balloons given 6 red and 6 green balloons. However, he stated that the result was 66 balloons. The other children did not represent quantities for any contextual situation.

Post-assessment performance for Group 4.

Procedural fluency. On the post-assessment, two children successfully counted beyond thirty, rather than the mid-20s on the pre-assessment. In addition, three children counted by twos, fives, and tens to 50 . For the majority of tasks, the children tracked counted and uncounted objects. However, on a task with a pictorial circular arrangement of objects, two children recounted the first of twelve objects placed in a circle giving resulting in over-counting the number of objects.

The children improved in their knowledge of the number sequence-all children correctly identified the "number after" a particular number word under 100. One child identified the "number after" number words to 200. Three children identified the "number before" number words to 50 with one child doing so to 200 . One child successfully compared more than two numerals by ordering from least to greatest.

Conceptual knowledge. All children in this group continued to recognize and apply one-to-one correspondence and cardinality. Two of 4 noted that, when counting objects, starting with a different object, the count did not change. Children demonstrated process with conservation of quantity. Whereas previously no child recognized that rearranging objects did not impact the quantity, for the post-assessment two of 4 children did.

As with the pre-assessment, when objects were placed into six groups of 
five, no child distinguished between the number of groups and the number of objects in a group. However, two children demonstrated the meaning of the "2" digit as 20 in the number 23. Three children identified the greater and the lesser of number words below 100, and two children correctly compared number words beyond 100 . One child correctly compared larger and smaller numerals. However, the other three children demonstrated inconsistent performance with numeral comparisons. These three children stated that 35 was more than 53, but did not explain why. However, they correctly identified that 53 was more than 35 when provided the number word.

Strategic competence. All children demonstrated strengths in strategic competence as they progressed with representing quantities and their relationships for contextualized word problems. All represented and solved a situation that asked them to determine the total number of balloons given 6 red and 6 green balloons. One child solved contextualized situations that included comparison (i.e., how many more is 10 stickers from 7 stickers) and missing addend situations by counting on. However, the other three children represented and combined all quantities for every contextualized situation.

\section{Discussion}

In this study we examined the strength and difficulties in early number of first grade children using a unique lens-examining student knowledge through the strands of mathematical proficiency. Below, we further discuss the results in relation to the specific area of difficulty and the extent to which these difficulties persisted or diminished.

\section{Specific Difficulties for Children Struggling with Early Number}

The results of this study point to the wide variety of difficulties for children. This is consistent with literature for children who are struggling. Examining the difficulties of struggling learners allowed us to see that all children demonstrated difficulties with strategic competence, but that children varied in their procedural fluency and conceptual understandings. For example, some children in the "mixed" group demonstrated a relatively strong knowledge of the counting sequence. However, they demonstrated difficulty keeping track of counted objects because they lacked successful procedures to keep track of what has been counted. The two children in the "high procedural, poor conceptual" group also demonstrated a relatively strong knowledge of the counting sequence and kept track of what was counted. However, despite these relative strengths, they demonstrated difficulty recognizing that the total number of items remained the same regardless of where the count started. Clearly, as Geary's (2004) subtypes sug- 
gest, these struggling learners are not heterogeneous as a group and may be struggling for different reasons. Moreover, unlike the research [e.g., Geary (2004), Butterworth (2003)], the findings demonstrate that these children demonstrate difficulty with concepts and skills other than arithmetic or magnitude. It is interesting to note that no "strong" group emerged that initially demonstrated deeper conceptual understanding, but poor procedural fluency. Those children who were mixed in their conceptual understanding and procedural fluency exhibited some of this tendency, but not to the extent represented by the other groups of children.

Also, within each group, we identified particular aspects of conceptual understanding and procedural fluency that were strengths for all children, whereas others were areas of difficulty for particular subsets of children. For example, similar to the findings of Geary and colleagues (see Geary \& Hoard, 2005), all children demonstrated a strong understanding of the concepts of cardinality and one-to-one correspondence. However, children varied considerably in their understanding and application of order irrelevance and conservation of quantity. In relation to procedural fluency, children varied in their application of proper tracking of objects, knowledge of the oral counting sequence, and of skip counting.

An interesting finding was the difference in performance for magnitude (i.e., determining which quantity was more or less) when children were provided with the same values orally and with numeric symbols. Magnitude performance has emerged in the literature as an important factor that appears to differentiate student early number knowledge (Geary \& Hoard, 2005; Noël, Rousselle, \& Mussolin, 2005). Most children on the pre- and post-assessment performed better on the oral magnitude items than on the numeric items with the same numbers. As has been found in other mathematical areas (e.g., Rousselle \& Noël, 2007), symbolic knowledge lags behind the informal mathematical knowledge. Children's continued difficulties on the post-assessment with performance on the magnitude tasks involving numeric symbols demonstrates the considerable difficulty that children experience with developing meaning for the numeric representation of quantities. In contrast, some children demonstrated strong magnitude performance with numeric symbols than oral items. Further research is necessary to examine why a few children develop symbolic magnitude knowledge prior to oral magnitude knowledge. The use of various representations in the assessment for similar constructs provided useful information about the extend of the children's knowledge in many areas, including their understanding of magnitude.

The study demonstrates that providing children with contextual problem situations may allow us to determine which children are struggling, but these tasks provide little insight into the specific mathematical difficulties that children may have. Assessment of specific number constructs are 
needed to determine student strengths and difficulties in their conceptual understanding and procedural fluency.

\section{Extent to Which Difficulties Persisted or Diminished}

The results demonstrate that all children made gains, but that a variety of knowledge barriers remained for these children at the end of first grade. Interestingly, differential rates of improvement for struggling learns following an intervention are common (e.g., Fuchs, Fuchs, \& Prentice 2004; Van Luit $\&$ Schopmann, 2000). It has been suggested that differential rates of learning imply that we need to better understand what the constructs children are struggling with.

The most impressive improvement for these children who were struggling in mathematics occurred in the area of strategic competence. What was encouraging to note in the post-assessment was that all children improved in their strategic competence, the lowest performing area on the pre-assessment. They extended their knowledge/skills in representing the various problem situations. However, some children (e.g., mixed performance group, poor-poor performance group) tended to represent quantities and combine them in situations where joining groups was not consistent with the structure of the problem. Such difficulty with representing situations has been noted by others (e.g., Van Luit \& Schopmann, 2000). In part, this may be because strategic knowledge requires drawing on procedural fluency, conceptual knowledge simultaneously with strategic knowledge (National Research Council, 2001). However, poor procedural fluency and/ or conceptual knowledge may interfere with the ability to both represent the problem and generate a correct solution (e.g., Durfour-Janvier, Bednarz, \& Belanger, 1987; Rittle-Johnson \& Alibali, 1999).

Different children demonstrated progress with various aspects of conceptual and procedural knowledge. However, some procedural difficulties persisted for particular children and some conceptual difficulties persisted for particular children. Other children within the various subgroups appeared to "jump ahead," making considerable gains in their conceptual, procedural, and strategic competence. Not all children necessarily improved on their pre-assessment difficulties by the end of first grade (e.g., overall low procedural knowledge to high procedural knowledge). However, they all made gains for some constructs. For example, some demonstrated difficulty tracking objects at the beginning of first grade, but consistently tracked object appropriately on the post-assessment.

Although we, as researchers, provided instruction that targeted the constructs in which the children demonstrated improvement, we cannot attribute solely any gains to our intervention. Undoubtedly, these children improved due to instruction they received in their first grade classrooms. Thus, we do not provide extensive details about the intervention, but we discuss the persistence and diminishing of student difficulties across the year. 


\section{Limitations of the Study}

Although the findings demonstrated various difficulties and strengths that the children had in early number and the impact of instruction targeted to meet their needs, these should be considered tentative and in need of further examination. Even though the tasks in the ENB were based on the extant literature (e.g., Fosnot \& Dolk, 2001) regarding what constructs contribute to development of early number understanding, the assessment was researcher developed and, therefore, in need of further refining and validation. For example, we noticed that some of the tasks needed to be restructured to draw out more information as to how the children approached the task. Additionally, for some of the constructs examined (e.g., place value), more tasks are needed to gain deeper understanding of what the children understand about a given construct.

It is possible that the children who participated in this study may not necessarily be 'struggling learners' as typically defined by the literature (e.g., lowest $25^{\text {th }}-30^{\text {th }}$ percentile according to a standardized measure). To identify the children for this study, we relied on teacher identification of children who were not doing well in mathematics as compared to their peers in their classroom. Further, we used the ENB to document that they were 'struggling' in the various early number constructs. And, although we identified a 'high procedural, high conceptual' group of children, these children were not consistently high across all constructs and demonstrated poor strategic competence, as did the other children in the study. However, to address this concern, we recommend the use of an additional measure (e.g., norm-referenced standardized mathematics measure) to further document that these children are indeed struggling.

Finally, more work is needed to gain a deeper understanding of the differing learning trajectories of the children who struggle with early number. While we worked with the children over the course of a year, this was insufficient for determining the implications of the strengths and weaknesses observed over time and for other mathematical domains. It is also unclear how constructs build on each other. For example, some children demonstrated limited understanding of certain constructs (e.g., poor knowledge of the counting sequence less than 30) that appear to be necessary for other constructs (e.g., oral magnitude including numbers beyond 30). It is recommended that future studies consider following children over the course of several years and focus on other constructs in number and operations beyond those studied here.

Instruction that targets specific areas of student difficulty should improve learning. While all children in our study improved, not all improved in every area. It is possible that our instruction was not targeted as needed by each child. Further research is needed to understand more fully the specific difficulties of children who are struggling in mathematics. 
Implications for Instruction

The findings of this study raise two instructional implications. First, the focus of the assessment needs to be multifaceted both in what is assessed and how. For example, a current trend in education is to apply curriculumbased measures (CBM) to identify and monitor progress children make related to number (i.e., Foegen, 2000; Foegen \& Deno, 2001; Fuchs, Hamlett, \& Fuchs, 1990, 1998, 1999; Lembke \& Foegen, 2009; Thurber, Shinn, \& Smolkowksi, 2002). Yet, these assessments typically target a small number of constructs related to number (e.g., number identification, magnitude [larger or smaller of two numbers], number sequence [fill in missing number for, typically, a sequence of 3 numbers]). In addition, they assess children primarily using numeric symbols. However, the findings from this study indicated that struggling learners might have difficulty in other constructs (e.g., order irrelevance, conservation of quantity) that can impede children from developing a rich understanding of number. Further, we found that a child may have strength in a construct that, if not assessed using other representational forms (e.g., orally, diagrams, manipulatives) beyond numeric symbols, may not get identified. This has implications that lead us to our second point, that the instructional needs of the 'struggling learner' are diverse.

The specific difficulties demonstrated by children in this study varied and, consequently, their instructional needs differed. This suggests that a 'one size fits all' instructional approach may not work for struggling learners. Closer attention needs to be provided to the instructional settings in which children engage. For example, for some children, it may be something as 'simple' as demonstrating and providing practice with how to keep track of what they have counted, whereas other children may need multiple opportunities and tasks involving various representational forms to develop an understanding of magnitude. Unfortunately, it has been suggested that the instruction many struggling learners receive is not designed to meet their needs (Gersten \& Chard, 1999). This may explain some of the achievement gap between children.

\section{References}

Baroody, A. J. (1992). The development of preschoolers' counting skills and principles. In J. Bideaud, C. Maljac, \& J. P. Fischer (Eds.), Pathways to number: Developing numerical abilities (pp. 99-126). Mahway, NJ: Erlbaum.

Butterworth, B. (1999). The mathematical brain. London: MacMillan.

Butterworth, B. (2005). The development of arithmetical abilities. Journal of Child Psychology and Psychiatry, 46(1), 3-18. 
Carpenter, T. P. \& Moser, J. M. (1984). The acquisition of addition and subtraction concepts in grades one through three. Journal for Research in Mathematics Education, 15(3), 179-202.

Clements, D. H. (2007). Early childhood mathematics learning. In F. K. Lester (Ed.) Second handbook of research on mathematics teaching and learning (pp. 461-555). Reston,VA: National Council of Teachers of Mathematics.

Clements, D. H., \& Sarama, J. (2009). Learning and teaching early math: The learning trajectories approach. New York: Routledge.

Cordes, S., \& Gleman, R. (2005). The young numerical mind: When does it count? In J. Campbell (Ed.), Handbook of mathematical cognition (pp. 127-142). New York: Psychology Press.

Dougherty, C. (2003). Nueracy, literacy and earnings: Evidence from the National Longitudinal Survey of Youth. Economics of Education Review, 22, 511-521.

Dufour-Janvier, B., Bednarz, N., \& Belanger, M. (1987). Pedagogical considerations concerning the problem of representation. In Claude Janvier (Ed.), Problems of representation in the teaching and learning of mathematics (pp. 109-122). Hillsdale, NJ: Lawrence Erlbaum Associates.

Foegen, A. (2000). Technical adequacy of general outcome measures for middle school mathematics. Diagnostique, 25, 174-203.

Foegen, A. \& Deno, S. (2001). Identifying growth indicators for lowachieving children in middle school mathematics. Journal of Special Education, 25, 4-16.

Fosnot, C. T., \& Dolk, M. (2001). Young mathematicians at work: Constructing number sense, addition, and subtraction. Portsmouth, NH: Heinemann.

Fuchs, L. S. (2005). Prevention research in mathematics: Improving outcomes, building identification models, and understanding disability. Journal of Learning Disabilities, 38, 350-352.

Fuchs, L. S., \& Fuchs, D. (2005). Enhancing mathematical problem solving for children with disabilities. The Journal of Special Education, 39, 45-57.

Fuchs, L. S., Fuchs, D., Hamlett, C. L., Powell, S. R., Capizzi, A. M., \& Seethaler, P. M. (2006). The effects of computer-assisted instruction on number combination skill in at-risk first graders. Journal of Learning Disabilities, 39, 467-475.

Fuchs, L. S., Fuchs, D., \& Prentice, K. (2004). Responsiveness to mathematical problem-solving instruction: Comparing children at risk of mathematics disability with and without risk of reading disability. Journal of Learning Disabilities, 31, 293-306.

Fuchs, L. S., Hamlett, C. L., \& Fuchs, D. (1990). Monitoring basic skills progress: Basic math computation. Austin, TX: PRO-ED. 
Fuchs, L. S., Hamlett, C. L., \& Fuchs, D. (1998). Monitoring basic skills progress: Basic math computation (2nd ed.). Austin, TX: PRO-ED.

Fuchs, L. S., Hamlett, C. L., \& Fuchs, D. (1999). Monitoring basic skills progress: Basic math concepts and applications. Austin, TX: PRO-ED.

Funkhouser, C. (1995). Developing number sense and basic computational skills in children with special needs. School Science and Mathematics, 95(5), 236-239.

Fuson, K. C. (1998). Children's counting and concepts of number. New York: Springer-Verlag.

Geary, D. C. (1990). A componential analysis of an early learning deficit in mathematics. Journal of Experimental Child Psychology, 49, 363-383.

Geary, D. C. (1993). Mathematical disabilities: Cognitive, neuropsychological, and genetic components. Psychological Bulletin, 114, 345-362.

Geary, D. C. (1994). Children's mathematical development: Research and practical applications. Washington, DC: American Psychological Association.

Geary, D. C. (2004). Mathematics and learning disabilities. Journal of Learning Disabilities, 37,4-15.

Geary, D. C., \& Hoard, M. K. (2005). Learning disabilities in arithmetic and mathematics: Theoretical and empirical perspectives. In J. I. D. Campbell (Ed.), Handbook of Mathematical Cognition (pp. 253-267). New York: Psychology Press.

Geary, D. C., Hard, M. K., Byrd-Craven, J., Nugent, L., \& Numtee, C. (2007). Cognitive mechanisms underlying achievement deficits in children with mathematical learning disability. Child Development, 78, 1343-1359.

Gelman, R. \& Gallistel, C. (1978). The child's understanding of number. Cambridge, MA: Harvard University Press.

Gersten, R., \& Chard, D. (1999). Number sense: Rethinking arithmetic instruction for children with mathematical disabilities. The Journal of Special Education, 44, 18-28.

Ginsburg, H. P., Inoue, N., \& Seo, K.-H. (1999). Young children doing mathematics: Observations of everyday activities. In J. V. Copley (Ed.) Mathematics in the early years (pp. 88-99). Reston, VA: National Council of Teachers of Mathematics.

Ginsburg, H., Klein, A., \& Starkey, P. (1998). The development of children's mathematical thinking: Connecting research with practice. In W. Damon, I. E. Siegel, \& K. A. Renninger (Eds.). Handbook of child psychology: Vol. 4. Child psychology in practice ( $5^{\text {th }}$ ed., pp. 401-476). New York: John Wiley \& Sons.

Goldin, G. A. (1997). Observing mathematical problem solving through task-based interviews. In A. R. Teppo (Ed.), Qualitative research methods in mathematics education, [Monograph] Journal for Research in Mathematics Education. (Vol. 9, pp. 40-62, 164-177). Reston, VA; NCTM 
Griffin, S. (2004). Building number sense with Number Worlds. Early Childhood Research Quarterly, 19, 173-180.

Griffin, S. (2005). Fostering the development of whole number sense: Teaching mathematics in the primary grades. In J. Bransford \& S. Donovan (eds.), How children learn: A targeted report for teachers (pp. 250302). Washington, DC: National Academics Press.

Griffin, S. (2007). Early intervention for children at risk of developing mathematical learning difficulties. In D. B. Berch \& M. M. M. Mazzocco (Eds.), Why is math so hard for some children? The nature and origins of mathematical learning difficulties and disabilities (pp. 373-395). Baltimore, MD: Paul H. Brookes.

Griffin, S. \& Case, R. (1997). Re-thinking the primary school math curriculum: An approach based on cognitive science. Issues in Education, 4(1), 1-51.

Jordan, N. C., Kaplan, D., Locuniak, M. N. \& Ramineni, C. (2007). Predicting first-grade math achievement from developmental number sense trajectories. Learning Disabilities Research \& Practice, 22(1), 36-46.

Jordan, N. C., Kaplan, D., Olah, L., \& Locuniak, M. N. (2006). Number sense growth in kindergarten: A longitudinal investigation of children at risk for mathematics difficulties. Child Development, 77, 153-175.

Klein, A., \& Starkey, P. (2004). Fostering preschool children's mathematical knowledge: Findings from the Berkeley math readiness project. In D. H. Glements, J. Sarama, \& A. DiBiase (Eds.), Engaging young children in mathematics: Standards for early childhood mathematics education (pp. 343-360). Mahwah, NJ: Lawrence Erlbaum Associates.

Klibanoff, R. S., Levine, S. C., Huttnelocher, J., Vasilyeva, M., \& Hedges, L. V. (2006). Preschool children's mathematical knowledge: The effect of teacher "Math Talk." Developmental Psychology, 42(1), 59-69.

Koontz, K. L., \& Cerch, D. B. (1996). Identifying simple numerical stimuli: Processing inefficiencies exhibited by arithmetic learning disabled children. Mathematical Cognition, 2(1), 1-23.

Kroesbergen, E. H., \& Van Luit, J.E. H. (2003;). Mathematics interventions for children with special educational needs. Remedial and Special Education, 24, 97-114.

Landerl, K., Bevan, A., \& Butterworth, B. (2004). Developmental dyscalculia and basic numerical capacities: A study of 8-9-year-old children. Cognition, 93, 99-125.

Landerl, K., Fussenegger, B., Moll, K., \& Willburger, E. (2009). Dyslexia and dyscalculia: Two learning disorders with different cognitive profiles. Journal of Experimental Child Psychology, 103(3), 309-324.

Lembke, E., \& Foegen, A. (2009). Identifying early numerary indicators for kindergarten and first-grade children. Learning Disabilities Research and Practice, 24, 12-20. 
Miles, M. B., \& Huberman, A. M. (1994). Qualitative data analysis: An expanded sourcebook (3rd ed.). Newbury Park, CA: Sage.

Montague, M., \& van Garderen, D. (2008). Evidence-based Interventions for children with learning and behavioral challenges. In R. J. Morris and N. Mather (Eds.). Research-based practice for effective mathematics instruction (pp. 236-257). New York, NY: Taylor \& Francis.

National Research Council. (2001). Adding it up: Helping children learn mathematics. Washington DC: The National Academics Press.

Noël, M-P., Rouselle, L., \& Mussolin, C. (2005). Magnitude representation in children: Its development and dysfunction. In J. I. D. Campbell (Ed.), Handbook of Mathematical Cognition (pp. 179-195). New York: Psychology Press.

Ostad, S. (1999). Developmental progression of subtraction studies: A comparison of mathematically normal and mathematically disabled children. European Journal of Special Needs Education, 14(1), 21-36.

Piaget, J., \& Szeminska (1952). The child's conception of number. London: Routledge and Kegan Paul.

Rittle-Johnson, B. \& Alibali, M. W. (199). Conceptual and procedural knowledge of mathematics: Does one lead to the other? Journal of Educational Psychology, 91, 175-190.

Rousselle, L., \& Noël, M-P. (2007). Basic numerical skills in children with mathematics learning disabilities: A comparison of symbolic vs non-symbolic number magnitude processing. Cognition, 102, 361-395.

Sarama, J., \& Clements, D. H. (2009). Early childhood mathematics education research: Learning trajectories for young children. New York: Routledge.

Starkey, P. (1992). The early development of numerical reasoning. Cognition and Instruction, 4, 93-126.

Steffe, L. P., \& Thompson, P. W. (2000). Teaching experiment methodology: Underlying principles and essential elements. In A. E. Kelly \& R. A. Lesh (Eds.), Handbook of Research Design in Mathematics and Science Education (pp. 267-306), Mahwah, NJ: Lawrence Erlbaum.

Swanson, H. L. (1999). Instructional components that predict treatment outcomes for children with learning disabilities: Support for a combined strategy and direct instruction model. Learning Disabilities Research \& Practice, 16, 109-119.

Thurber, R. S., Shinn, M. R., \& Smolkowski, K. (2002). What is measured in mathematics tests? Construct validity of curriculum-based mathematics measures. School Psychology Review, 30, 363-382.

Tournaki, N. (2003). The differential effects of teaching addition through strategy instruction versus drill and practice to children with and without learning disabilities. Journal of Learning Disabilities, 36, 449-458.

Van Luit, J. E. H. \& Schopmann, E. A. M. (2000). Improving early numer- 
ary of young children with special needs. Remedial and Special Education, 21(1), 27-40.

Woodward, J., \& Montague, M. (2002). Meeting the challenge of mathematics reform for children with LD. The Journal of Special Education, 36, 89-101.

Wright, R. J., Stewart, R., Stafford, A., \& Cain, R. (1998). Assessing and documenting student knowledge and progress in early mathematics. In S. B. Berenson, K. L. Dawkins, M. Blanton, W. N. Coulombe, J. Kolb, K. Norton, \& L. Stiff (Eds.), Proceedings of the Twentieth Annual Meeting of Mathematics Education, 1, 211-216.

Appendix

Descriptors of the Procedural and Conceptual Knowledge for Various Constructs

Knowledge of the Number Sequence and Skep Counting

Low Procedural

Cannot correctly recite the counting sequence to 30 and cannot count by $2 \mathrm{~s}, 5 \mathrm{~s}$, or $10 \mathrm{~s}$ High Procedural

Can rote recite the number sequence, usually to more than 29 . State a number before or following a number without counting through the counting sequence. Can count by $2 \mathrm{~s}$, $5 \mathrm{~s}$, and $10 \mathrm{~s}$.

\section{Low Conceptual}

When determining a missing quantity or the total amount of objects, the children must count back through the number sequence to determine the missing quantity.

High Conceptual

When determining a missing quantity or the total amount of objects, able to use the number before or after to determine the missing quantity.

Tracking and One-to-one Correspondence

Low Procedural

Not able to consistently keep track of counting objects one at a time. Loses track of what is counted each time.

High Procedural

For all tasks, can keep track of counting objects one at a time. Counts various arrangements to assure that each object is counted only once.

High Conceptual

Know that for each item touched, say one.

Order Irrelevance

Low Conceptual

Does not recognize that you can count starting with any object, or only counts the amount from that point.

High Conceptual

Recognizes that you can count starting with any object. 


\section{Conservation of Quantity}

Low Conceptual

Does not recognize that you can rearrange objects and maintain the same quantity. High Conceptual

Recognizes that you can rearrange objects and maintain the same quantity without recounting.

Cardinality

Low Conceptual

Difficulty recognizing that the last count is the number of objects.

High Conceptual

Recognizes that the last count is the number of objects.

Unitising

Procedural

The child can put objects into groups.

Low Conceptual

Can view a quantity in only one way (total number of objects or number of groups).

Restate the number of groups for the number of objects.

High Conceptual

Can view a quantity in more than one way. For example, the child recognizes that they can state the number of groups or the number of objects to represent the total.

Place Value

Low Conceptual

Unable to distinguish between / unable to recognize that the position of a digit in a number impacts the quantity.

High Conceptual

Able to distinguish that the position of a digit has meaning and represents specific powers of ten (e.g., tens, ones, etc.).

Magnitude (oral and symbolic)

Low Conceptual

Counts through the number sequence each time to determine bigger or smaller number or is not sure what to attend to and 'grabs' a number to try, or compares single digits within the number. May be able to do numbers from 0-20 but not beyond.

High Conceptual

Uses decades or centuries as benchmarks, or talks about numbers in relation to one another. Can work with numbers larger than 20. 